\title{
Vaginal delivery after robot-assisted uterine artery- preserving radical trachelectomy for early-stage cervical cancer
}

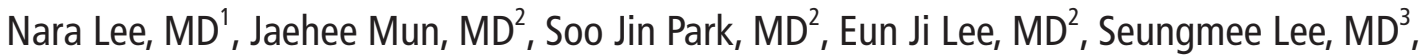 \\ Hee Seung Kim, MD, PhD² \begin{abstract}
Research Institute, Seoul National University College of Medicine, Seoul; ${ }^{3}$ Department of Obstetrics and Gynecology, Keimyung University School of Medicine, Daegu, Korea
\end{abstract} \\ 'Department of Obstetrics and Gynecology, CHA Gangnam Medical Center, CHA University, Seoul; ${ }^{2}$ Department of Obstetrics and Gynecology, Cancer
}

Radical trachelectomy is conducted in women with early stage cervical cancer who strongly desire fertility preservation. To improve fertility outcomes, the preservation of the uterine artery has been suggested, which can be feasible by minimally invasive surgery using laparoscopy or robots. Although cesarean delivery is required for maternal and fetal health, vaginal delivery is a concern due to the fast delivery process of risk of preterm labor. We report a case of a 32-year-old nulliparous woman with stage IB1 cervical cancer who underwent robot-assisted uterine artery-preserving radical trachelectomy for improving fertility. This case is meaningful because she delivered by vaginal delivery after incision of the fibrotic ring at the level of uterovaginal anastomosis because delivery proceeded too quickly prior to the preparation of the cesarean delivery.

Keywords: Cervical cancer; Robot-assisted radical trachelectomy; Preservation of the uterine arteries; Vagianl delinvery

\section{Introduction}

Since radical vaginal trachelectomy using the Dargent approach was introduced to preserve fertility in 1994 [1], radical trachelectomy has become an alternative option for radical hysterectomy in young women with early stage cervical cancer who strongly wish to preserve fertility, and has been traditionally performed via a vaginal or abdominal approach. Despite being minimally invasive procedure, vaginal radical trachelectomy is a difficult approach due to the narrow field of view through the vagina, whereas abdominal radical trachelectomy has advantages such as a wider view for resection and relatively shorter learning curve. However, the uterine arteries have been sacrificed in both procedures up till now despite the increasing expectation for better functionality of the remaining uterus $[2,3]$.

Recently, laparoscopic or robot-assisted radical trachelectomy has been activated with the development of minimally invasive surgery. Therefore, delicate surgery preserving the pelvic autonomic nerves or uterine arteries has been more feasible [4]. Recurrence rates appear to be the same regard- less of whether the trachelectomy is performed via the vaginal, abdominal, laparoscopic, or robotic approach.

However, obstetric limitations, including preterm birth and cesarean delivery, are still unresolved in women treated with radical trachelectomy [5]. Women were advised to deliver by cesarean section for permanent isthmus preservation. However, in women who have undergone trachelectomy, it may be difficult to assess preterm birth because mid-trimester miscarriages and preterm labor may present with painless

Received: 2019.07.19. Revised: 2020.10.30. Accepted: 2020.12.28. Corresponding author: Hee Seung Kim, MD, PhD

Department of Obstetrics and Gynecology, Seoul National University College of Medicine, 101 Daehak-ro, Jongno-gu, Seoul 03080, Korea

E-mail: bboddi0311@gmail.com

https://orcid.org/0000-0001-6876-8671

Articles published in Obstet Gynecol Sci are open-access, distributed under the terms of the Creative Commons Attribution Non-Commercial License (http://creativecommons. org/licenses/by-nc/3.0/) which permits unrestricted non-commercial use, distribution, and reproduction in any medium, provided the original work is properly cited.

Copyright $\odot 2021$ Korean Society of Obstetrics and Gynecology 


\section{Obstetrics \& Gynecology Science}

Vol. 64, No. 3, 2021

progressive dilatation of the neo-cervix. Thus, we introduce a case of vaginal delivery due to rapid fetal descent after robot-assisted uterine artery-preserving radical trachelectomy for early stage cervical cancer.

\section{Case report}

\section{Patients information, diagnosis, and surgery}

A 32-year-old nulliparous woman visited because of atypical squamous cells, to consider high-grade squamous intraepithelial lesions on cervical cytology. Cervical intraepithelial neoplasia III was seen on cervical biopsy; thus, we conducted loop electrical excision procedure, and the pathologic finding demonstrated microinvasive squamous cell carcinoma with a vertical invasion of $1 \mathrm{~mm} / 3 \mathrm{~mm}$ in total thickness and horizontal spread of $4 \mathrm{~mm}$ without lymphovascular space invasion. To preserve her fertility, cold knife conization was performed again because of a positive resection margin showing high-grade dysplasia. However, the pathologic
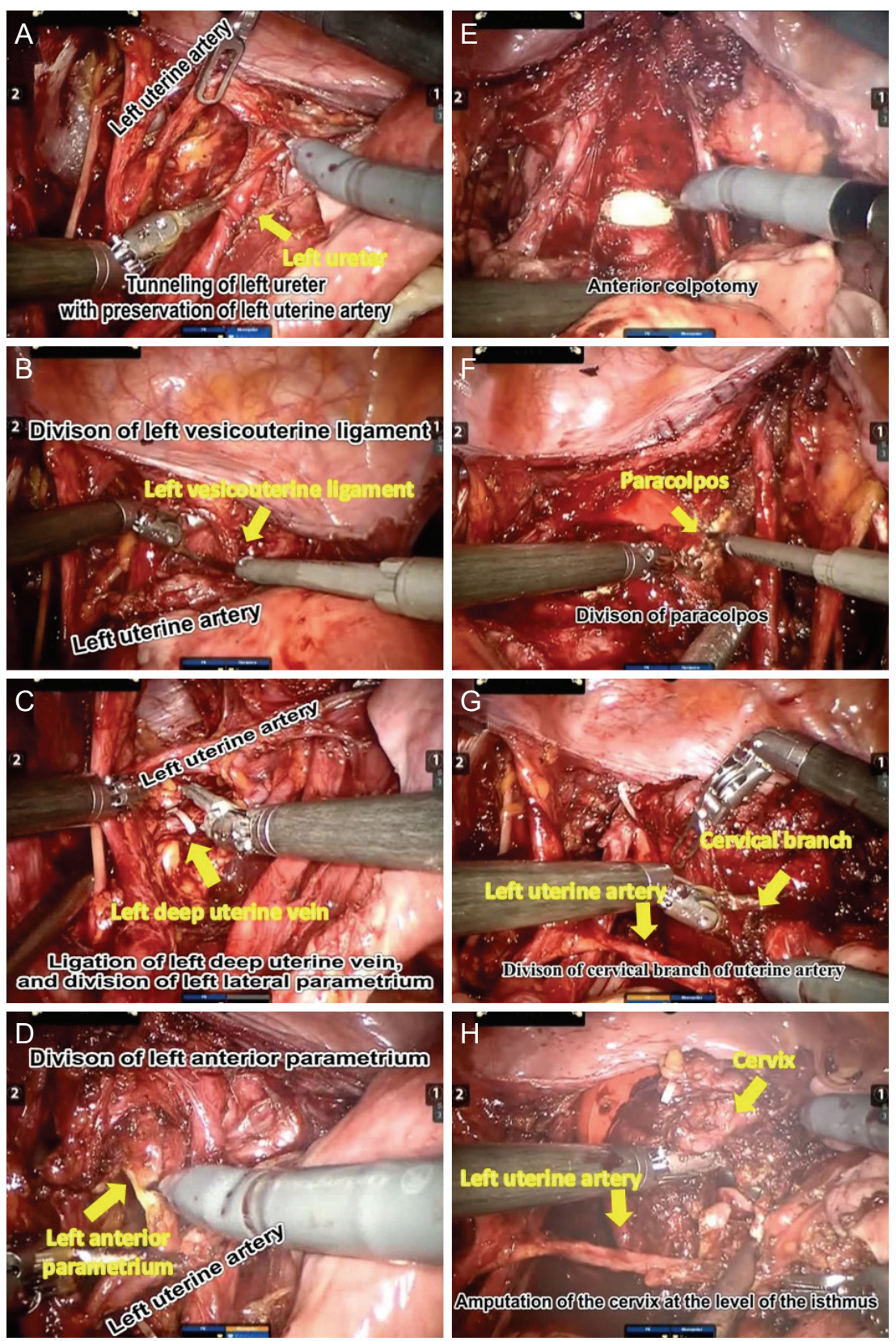

Fig. 1. Procedures for preserving the uterine artery in robot-assisted radical trachelectomy: $(A)$ tunneling of the left ureter with the preservation of the left uterine artery; (B) division of the left vesicouterine ligament; (C) ligation of the left deep uterine vein; (D) division of the left anterior parametrium; (E) anterior colpotomy; (F) division of the paracolpos; $(G)$ division of the cervical branch of the left uterine artery; and $(\mathrm{H})$ amputation of the cervix at the level of the isthmus. 


\section{Obstetrics \& Gynecology Science}

Nara Lee, et al. Robot-assisted radical trachelectomy

findings showed invasive squamous cell carcinoma with a vertical invasion of $4.5 \mathrm{~mm} / 10 \mathrm{~mm}$ in total thickness and horizontal spread of $8 \mathrm{~mm}$ with negative surgical margin on the 12 to 3 o'clock specimen. To establish the clinical stage of cervical cancer, we performed computed tomography (CT) and magnetic resonance imaging (MRI) of the pelvis, which demonstrated no evidence of local tumor invasion or lymph node metastasis. Positron emission tomography-CT showed no definite malignant lesion, and sigmoidoscopy and cystoscopy showed no abnormal findings. Finally, she was diagnosed with stage IB1 cervical cancer, and we proceeded with a robot-assisted uterine artery-preserving radical trachelectomy, considering her strong desire to preserve fertility.

For this surgery, a four-arm da Vinci Si system (Intuitive Surgical, Inc., Sunnyvale, CA, USA) with a standard port placement and a set of robotic instruments for the pelvic surgery were used for the procedure [6]. In the pelvic cavity, we identified one enlarged lymph node in the left external iliac artery area, which was negative for malignant cells upon frozen section. Then, we performed systematic pelvic lymphadenectomy and para-aortic lymph node sampling until the level of the inferior mesenteric artery. Thereafter, radical trachelectomy preserving the uterine arteries was performed (Fig. 1), and a cerclage was placed with a transvaginal MERSILENE ${ }^{\circledR}$ polyester fiber suture. Uterovaginal reanastomosis was made through the vaginal approach, and a 6fr 2-way Foley catheter was placed in the uterine cavity to maintain patency.

Total operation time was 330 minutes, and blood loss was approximately $200 \mathrm{~mL}$. The final pathological examination showed no residual tumor in a $3.5 \mathrm{~cm}$-sized specimen of the cervix and vagina, and no lymph node metastasis among the 17 resected lymph nodes. Six months after surgery, no abnormal findings were observed (Fig. 2), and she was deemed fit for pregnancy through assisted reproductive technology.

\section{Fertility care}

She received clomiphene citrate for five days from the second day of her menstrual cycle, and human menopausal gonadotropin for seven days followed by successful implantation with intrauterine insemination 14 months after surgery. Progesterone intramuscular injection and vaginal tablets were used for implantation support.

\section{Obstetric care}

As with other mothers, nuchal translucency measurements and pregnancy-associated plasma protein-A levels were checked at 12 weeks of gestation, and a Quad test was performed at 16 weeks of gestation. The integrated test showed low risk. She had no risk factors except for antibiotic treatment with repeated acute pyelonephritis during pregnancy.

She presented with abdominal pain at 21 weeks and three days of gestation, and a $2 \mathrm{~cm}$ bulge of amniotic sac was observed on ultrasonography and speculum examination. Thereafter, she was hospitalized and treated with prophylactic antibiotics due to incompetent internal os of the cervix. At 22 weeks and one day of gestation, membrane rupture occurred. At 24 weeks and three days of gestation, uterine contraction occurred and patient was started on tocolytics. Although she had received tocolytics for suppression of uterine contractions, regular contraction and fetal descent proceeded abruptly at 26 weeks and 3 days of gestation. Since the fetus had already descended to stage 3 and there was no fetal heart rate deceleration, we decided to proceed vaginal delivery instead of preparing for cesarean section. Because the fibrotic ring at the level of uterovaginal anastomosis interfered with fetal descent, we removed the cerclage knot and incised the ring with scissors at 2,10 o'clock to facilitate vaginal delivery.

As a result, she immediately delivered a preterm male baby with no anomalies, weighing $830 \mathrm{~g}$, with APGAR scores of

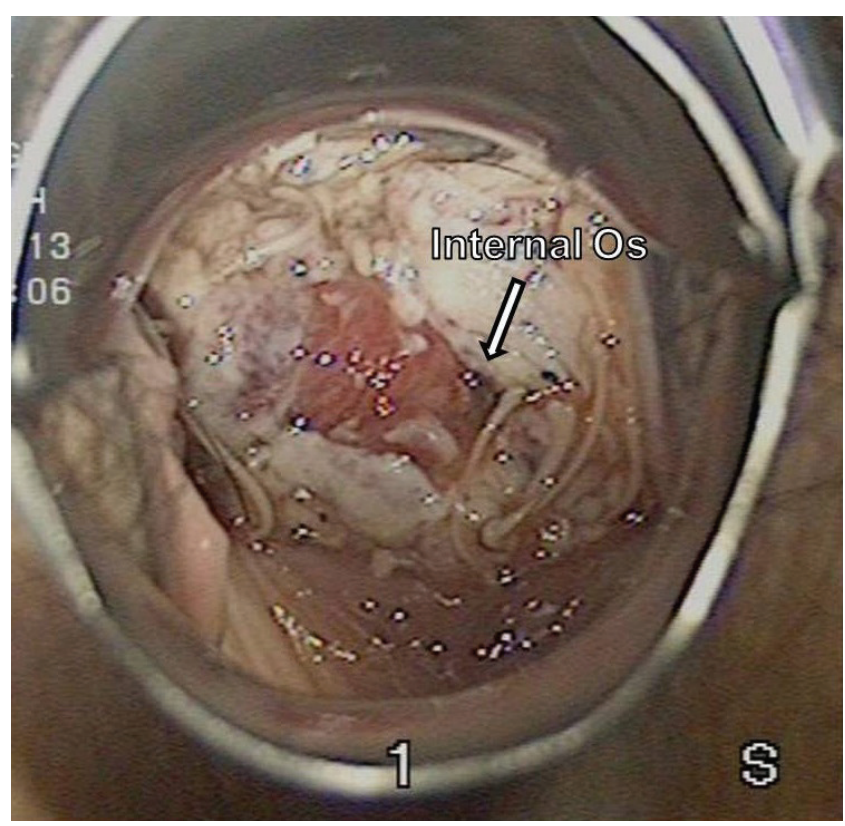

Fig. 2. Postoperative view of the vaginouterine reanastomosis site at six months after surgery. 


\title{
Obstetrics \& Gynecology Science
}

\author{
Vol. 64, No. 3, 2021
}

1 and 4 at 1 and 5 minutes, respectively. Umbilical cord PH 7.334 showed no fetal hypoxia. After delivery, the incision wound healed without suture as with the lacerated cervix. Although the baby had been treated at the neonatal intensive care unit, he presented with no complications, and was healthy five years after delivery.

\section{Discussion}

Radical trachelectomy is a treatment option for women with early stage cervical cancer who want to preserve their fertility. Till date, more than 900 cases of radical trachelectomy have been reported, resulting in 300 pregnancies and 196 live births, suggesting the pregnancy rate of $15-30 \%[7,8]$. Despite no evidence that the preserving the uterine arteries during trachelectomy may improve fertility in women with early-stage cervical cancer, the importance of preservation of the uterine artery for improved fertility has been reported in several studies, where womens treated with the uterine artery embolization showed higher rates of preterm delivery and malpresentation (odds ratios, 6.2 and 4.3) than those treated via myomectomy [9]. This suggests that the preservation of the uterine arteries may be beneficial in subsequent pregnancies. Although the preserved uterine arteries have been reported to have an approximately $88 \%$ chance of occlusion after surgery [10], their preservation is still of value if more delicate surgery is performed in a larger field of view by laparoscopy or robots.

However, obstetric complications, including preterm labor and premature rupture of membranes, are major obstacles that make women with early stage cervical cancer reluctant to undergo radical trachelectomy. Recent studies have reported that the rate of preterm delivery (24-37 weeks) was $25-28 \%$, which is a four times more than that in the normal population $[11,12]$. Moreover, premature delivery commonly arises following premature rupture of membranes, the mechanism of which is due to either cervical incompetence or ascending infection $[13,14]$. Although cerclage may reinforce the cervix and help maintain mechanical support of the fetus, an extremely short cervix and a high risk of infection are still major risk factors for preterm delivery in women who underwent radical trachelectomy. Thus, close monitoring of the mother and care of the fetus in a neonatal intensive care unit should be supported.
Furthermore, cesarean delivery is preferred after radical trachelectomy because vaginal delivery can lead to uterine rupture and subsequent massive hemorrhage [15]. To the best of our knowledge, this is the first case report of vaginal delivery after radical trachelectomy. Vaginal delivery was only attempted incision of the fibrotic ring at the level of uterovaginal anastomosis because delivery proceeded too quickly before the preparation of the cesarean delivery, and fetal deceleration rapidly much with the compression of the fetal head to the fibrotic ring. Thus, we believe that this case of vaginal delivery is a lucky success, and cesarean delivery is still the treatment of choice for women who underwent radical trachelectomy.

In conclusion, robot-assisted radical trachelectomy can be considered for women with early stage cervical cancer who strongly wish to preserve their fertility, and the preservation of the uterine arteries may be feasible by laparoscopy or robots for improving fertility outcomes. Moreover, vaginal delivery can be attempted by incising the fibrotic ring at the level of uterovaginal anastomosis when the fibrotic ring interferes with fetal descent and if delivery rapidly proceeds before adequate preparation of cesarean delivery.

\section{Conflict of interest}

No conflict of interest relevant to this article was reported.

\section{Ethical approval}

Ethical Committee approval was received for this study from the Ethics Committee of Seoul National University School of Medicine, dated 06.11.2019 and numbered H-1906-022-1038.

\section{Patient consent}

Written informed consent and the use of images from patients are not required for the publication.

\section{Funding information}

None. 


\section{Obstetrics \& Gynecology Science}

Nara Lee, et al. Robot-assisted radical trachelectomy

\section{References}

1. Dargent D. Pregnancies following radical trachelectomy for invasive cervical cancer. Gynecol Oncol 1994;52:105.

2. Kim HS, Choi CH, Lim MC, Chang SJ, Kim YB, Kim $M A$, et al. Safe criteria for less radical trachelectomy in patients with early-stage cervical cancer: a multicenter clinicopathologic study. Ann Surg Oncol 2012;19:19739.

3. Li J, Li Z, Wang H, Zang R, Zhou Y, Ju X, et al. Radical abdominal trachelectomy for cervical malignancies: surgical, oncological and fertility outcomes in 62 patients. Gynecol Oncol 2011;121:565-70.

4. Hong DG, Lee YS, Park NY, Chong GO, Park IS, Cho YL. Robotic uterine artery preservation and nerve-sparing radical trachelectomy with bilateral pelvic lymphadenectomy in early-stage cervical cancer. Int J Gynecol Cancer 2011;21:391-6.

5. Al-Niaimi AN, Einstein MH, Perry L, Hartenbach EM, Kushner DM. Uterine artery sparing robotic radical trachelectomy (AS-RRT) for early cancer of the cervix. Int J Gynaecol Obstet 2011;112:76-80.

6. Persson J, Kannisto P, Bossmar T. Robot-assisted abdominal laparoscopic radical trachelectomy. Gynecol Oncol 2008;111:564-7.

7. Schneider A, Erdemoglu E, Chiantera V, Reed N, Morice $P$, Rodolakis $A$, et al. Clinical recommendation radical trachelectomy for fertility preservation in patients with early-stage cervical cancer. Int J Gynecol Cancer 2012;22:659-66.

8. Klemm P, Tozzi R, Köhler C, Hertel H, Schneider A. Does radical trachelectomy influence uterine blood supply? Gynecol Oncol 2005;96:283-6.

9. Goldberg J, Pereira L. Pregnancy outcomes following treatment for fibroids: uterine fibroid embolization versus laparoscopic myomectomy. Curr Opin Obstet Gynecol 2006;18:402-6.

10. Tang J, Li J, Wang S, Zhang D, Wu X. On what scale does it benefit the patients if uterine arteries were preserved during ART? Gynecol Oncol 2014;134:154-9.

11. Jolley JA, Wing D. Pregnancy management after cervical surgery. Curr Opin Obstet Gynecol 2008;20:528-33.

12. Plante M. Vagianl radical trachelectomy: an update. Gynecol Oncol 2008;111(2 Suppl):S105-10.

13. Shepherd JH, Spencer C, Herod J, Ind TE. Radical vaginal trachelectomy as a fertility-sparing procedure in women with early-stage cervical cancer-cumulative pregnancy rate in a series of 123 women. BJOG 2006;113:719-24.

14. Ishioka S, Endo T, Hayashi T, Baba T, Umemura K, Saito T. Pregnancy-related complications after vaginal radical trachelectomy for early-stage invasive uterine cervical cancer. Int J Clin Oncol 2007;12:350-5.

15. Kay TA, Renninson JN, Shepherd JH, Taylor MJ. Successful pregnancy following radical trachelectomy and in vitro fertilization with ovum donation. BJOG 2006;113:965-6. 